University of Nebraska - Lincoln

DigitalCommons@University of Nebraska - Lincoln

June 1988

\title{
Values, Beliefs, and Attitudes in a Sociotechnical Setting
}

F. Gregory Hayden

University of Nebraska-Lincoln, ghayden1@unl.edu

Follow this and additional works at: https://digitalcommons.unl.edu/econfacpub

Part of the Economics Commons

Hayden, F. Gregory, "Values, Beliefs, and Attitudes in a Sociotechnical Setting" (1988). Economics Department Faculty Publications. 9.

https://digitalcommons.unl.edu/econfacpub/9

This Article is brought to you for free and open access by the Economics Department at DigitalCommons@University of Nebraska - Lincoln. It has been accepted for inclusion in Economics Department Faculty Publications by an authorized administrator of DigitalCommons@University of Nebraska - Lincoln. 


\title{
Values, Beliefs, and Attitudes in a Sociotechnical Setting
}

\author{
F. Gregory Hayden
}

Yngve Ramstad has recently inquired about how to define the components of the social fabric matrix and digraph system [Ramstad 1986; Hayden 1982a, 1982b]. To answer that question with regard to three of the matrix's components is the purpose of this article. The article will present, expand, and refine the author's introductory work on values, beliefs, and attitudes for the social fabric matrix [Hayden 1977, 1985]. There are numerous meanings the word "values" evokes among institutionalist readers; for examples: social value, instrumental valuing, technological values, and valuation. Those concepts are concerned with "what ought to be," while the definition of values set out below is intended to describe "what is."

\section{Cultural Values}

Values are a sub-set of culture. A culture is a collective systemic mental construct of the superorganic and supernatural world. It does not exist as a whole in any single mind. It contains a group's abstract ideas, ideals, and values from the superorganic and supernatural world, and it is found in legends, mythology, supernatural visions, folklore, literature, elaborated superstitions, and sagas. Culture is provided by tradi-

The author is Professor of Economics, University of Nebraska-Lincoln. This article was presented at the Annual Meeting of the Association for Evolutionary Economics, 27-30 December 1987. 
tion and not by the human agent or social institutions. This means culture is not determined by instrumental valuing, or discretionary decisions, or technological change. We need to recognize that a culture is separate in definition, meaning, and performance from society. Culture, although a powerful directive and prescriptive influence on society, is cerebral, while society is the set of sociotechnical relationships that direct behavior patterns. Society changes regularly but culture does not; a culture lives on even after a society is destroyed.

\section{Cultural Values as Criteria}

Values are cultural criteria or evaluative standards for judgment with regard to what is ideal. They are the ultimate criteria in the sense that they are above institutions and people. They are the focal criteria that are the locus to which all social criteria attempt to conform. For a welladjusted society, instrumental policymakers should design sociotechnical beliefs and patterns to be in conformance with cultural values.

A problem in the social sciences regarding cultural values is that scientists attempt to apply the concepts, which have been developed for analyzing society, to analyzing values. For purposes of analysis and relevant policy, we need to distinguish cultural values from other entities that are sometimes referred to as values. Cultural values are not desires, motives, pleasures, beliefs, attitudes, or tastes. Neither are they determined by instrumental valuing, discretionary decision-making, nor technological change. Neither do they conform to Marxist labor theories of value. Neither can they be equated to nor measured by price. Neither are they prioritized along some hierarchical cardinal or ordinal scale. Neither can they be added up as production nor functionalized as a "social welfare function." They are criteria. The concepts mentioned in this paragraph are concepts taken from societal analysis. They are not appropriate for the analysis of cultural values.

The analysis of a group's stories, holy books, legends and so forth reveals basic criteria common to all those sources. Those same criteria guide the group's social relationships. While the cultural values are limited in number to a dozen or so, the belief criteria guided by values number in the thousands.

Some Western values that have been the same for centuries include: (1) strong domination of nature by man, (2) atomistic conceptualization, (3) extensive hierarchical relationships, (4) flowing time, (5) dualistic thought, and (6) dynamic expansiveness. They are found in our legends, songs, religious myths, and literature, and are acted out in our social arrangements. Although these values have been constant for cen- 
turies, they have been expressed through different societal arrangements in different eras.

When we analyze folk tales and literature, we find that our heroes and gods operate in a system consistent with the above-listed cultural values. Authority and power are distributed over a wide hierarchical range, whether the folktales are about kings, queens, and barons, or corporate CEOs, vice-presidents, and comptrollers, or chancellors, associate professors, and assistant instructors, or gods, archangels, and devils. They all operate in a dynamic world where the existence of growth and creation is good (how much empire taken, how many souls saved, how many articles published), where the natural environment exists to be subdued, (slaying dragons, or damming raging rivers, or draining evil swamps), where good and evil are clear and dualistically structured (heaven and hell, labor and capital, demand and supply, profit and cost), and where the faster it is all processed, the better (it is a sin to. waste passing time).

Cultural values are transcendental across all aspects of culture and society. They assert themselves even in the unconscious spheres of existence. Because they are transcendental it is impossible for the human agent to change them. They are constantly being reinforced through culture, in the workplace, by movies, television, language, linguistic structure, and so forth. Their reinforcement is direct in the culture, and indirect through beliefs in society. The values are the evaluative criteria for establishing which actions and relationships are worthy of providing satisfaction and which should be desirable. Cultural values are not goals or actions, they are end-existence criteria by which goals and actions are to be judged. They are the basic and primary prescriptive forces that circumscribe societal norms, which in turn serve as criteria for institutional patterns. Although powerful and transcendental, cultural values are not deterministic because numerous alternative beliefs and institutional arrangements can satisfy a set of criteria. They limit and exclude but do not determine.

Because there has not been adequate distinction made between culture and society, not enough work has gone into designing indices to determine whether basic cultural values are being met. Given their importance, they should be ignored least of all. This is true for at least two reasons. First, resources can be wasted if the economy is directed by trifles. Distractions such as pleasure, interest, or compulsions may misdirect energies and resources outside the spectrum of activities that culminate in worthy activity patterns; dissatisfaction will set in and it will be expensive to abandon concomitant economic structures. Second, a lack of concern for cultural values leads to alienation with its accom- 
panying psychological problems, social malaise, and loss of economic productivity.

Just as we accept the scientific fact that goose down is softer than door knobs, and therefore do not use the latter to stuff pillows, we need to accept anthropological findings that there are cultural criteria that must be taken as given. Thus if we have a culture with a strong emphasis on dominating nature, we cannot solve environmental problems by designing programs to live in harmony with nature. Instead we should design programs that allow us to dominate without adverse repercussions. For example, there are ways to cultivate the soil that cause high rates of soil erosion, and there are ways to cultivate it that result in building the soil. Both allow for humans to express the domination trait; however, the latter does it in a manner that serves civilization.

Although anything short of genocide will not destroy a culture, an inability to express it will lead to a deteriorating condition of any group. The case of Native Americans in the United States is an example of such extreme deterioration. Because they were not able to express their values in their social and economic activities, their condition became a deteriorating one of alienation, alcoholism, and crime. If the majority society is not to create for itself what it created of Native Americans, efforts must be devoted to cultural welfare and value indicators.

\section{Social Beliefs}

Whereas cultural values are transcendental, social beliefs are activity- and institution-specific. The connection between values and beliefs, as indicated in Figure 1, provides the bridge between culture and society. Society is a set of relationships, not people, or bronze, or horses. The relationships are determined by institutions, which are patterns of activity that prescribe the roles for the elements (humans, animals, machines, trees) as well as the emotional commitments for the human element.

Some institutionalists have attempted to convince us that social institutions are consequences of instrumental valuing. Not only is that lacking evidence with regard to the vast majority of institutions, it is also inconsistent with the vast majority of institutionalist writing. We do not want to fall into the trap of assuming there is some deterministic process that automatically selects optimal social institutions.

As Walter Neale stated in his recent explanation of social institutions, an institution is identified by three characteristics: (1) there are patterns of activities, (2) there are rules giving the activities repetition, stability, and order, and (3) there are folkviews explaining or justifying 


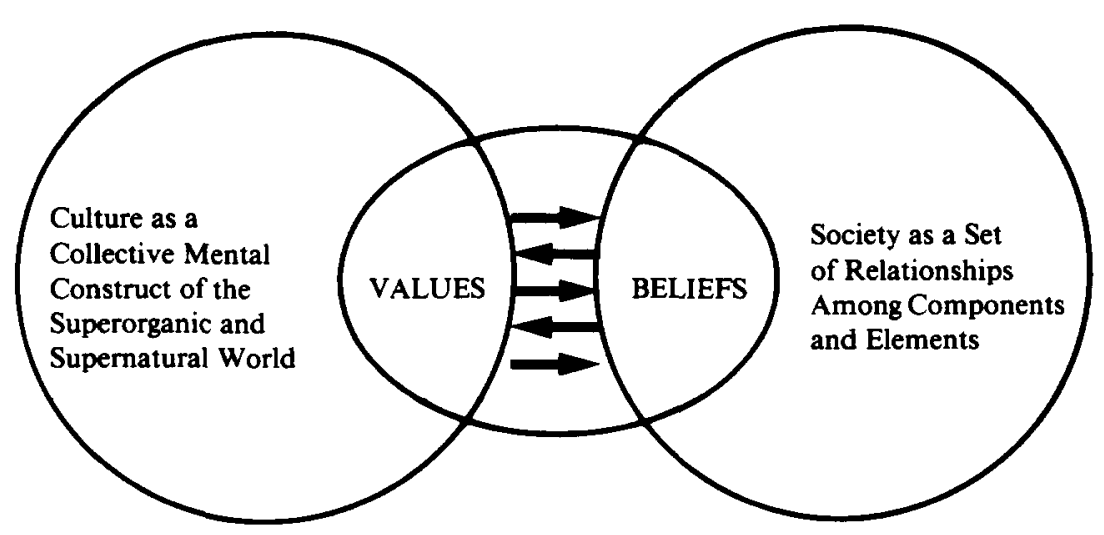

Figure 1. Cultural and Society Related Through Values and Beliefs

the activities and the rules [Neale 1987]. The latter are the social beliefs. The answers to the questions about why "reflect the beliefs of the participants about how and why the activities are carried on or beliefs about what justifies or ought to justify the activities" [Neale 1987].

Since institutions are accepted as normal behavior, the belief criteria justifying them are referred to as norms. These normalized beliefs are the societal criteria for what is good and bad, correct or incorrect and are, in a stable non-alienated society, in conformity with cultural values. Each institution and activity will have a cluster of beliefs that are specific to that institution. Each and every belief conforms to all cultural values. An ideology is the systematization of congruent societal beliefs. Thus, in analyzing a social or economic problem, ideological analysis is very important.

To determine economic efficiency, it is necessary to consider whether institutions and economic processes fulfill cultural values and societal beliefs. Maximizing production levels or optimizing around production functions and consumer preferences are not the core efficiency concerns. Efficiency is a matter of meeting social criteria. If this is understood, the decision on the part of courts and governmental agencies regarding job safety, hiring quotas, and hostile takeovers would not be considered external interferences. They are economic efficiency concerns from a sociocultural point of view. 
Searching out belief criteria is an activity as varied as the institutions themselves. In a modern society, beliefs are usually expressed through codification in statutes, court decisions, and legal opinions; and legal criteria are established for judging everything from university hiring procedures to water quality. Beyond the statutes, the agency rules, regulations, and operating procedures are where the real belief criteria are found. To find the criteria that guide business and industrial institutions, get a copy of the Standard Operating Procedure (SOP) Manual; to find labor criteria in union shops, go to the union contract, and so forth. Of course a great part of the world does not have its social belief criteria so handily codified.

We should begin to see that social beliefs are the battle zone between culture and society when there is social change. It was explained that beliefs give rise to institutional means of expression. Cultural values are therefore made obligatory on societies' members by institutional arrangements. On the other hand it was explained that social beliefs are derived from the normalized institutional pattern. It may appear that there is a conflict. There is. In the sociocultural world, beliefs must serve both masters-the cultural values and the social institutions. If social institutions are changed for some reason, let us say because of technological innovation, new beliefs will develop consistent with the new pattern of behavior. The new patterns and beliefs may be inconsistent with the unchanging values. The inconsistency leads to alienation and social disorientation, which in turn leads to new social processes. This is usually a haphazard trial-and-error process. This is one of the reasons the social fabric matrix framework is needed to assist in value application and social alignment for the development and legitimation of new institutions, and in economic development efforts.

Social beliefs and institutions establish roles for the elements. For each institutional situation there are obligations, permissions, and prohibitions for the elements. The human element is socialized to respond to signs and symbols in order to fulfill the responsibilities and duties of a situation. These responses are referred to as attitudes. Beliefs and institutions regulate peoples' attitudes toward signs and symbols and thereby regulate behavior.

\section{Attitudes as Human Responses}

Attitudes represent several social beliefs focused on a specific object or situation. It is through attitude responses that the machines are minded, the children get fed, the flags are saluted, and the trees cut. It 
is through attitude theory that the human actor is brought into institutionalist theory. Attitudes are held by specific people, about specific objects and situations.

After hedonism and instinct theory fell into scientific disrepute, inner drives and motives were postulated as the mechanisms from within the human that arouse, direct, and sustain activity. The Dictionary of $B e^{-}$ havioral Science defines a motive as "a state within an organism which energizes and directs him toward a particular goal" [Wolfman 1973]. Reductionists assumed that attitudes come from the actor's motives. They assumed they could reduce to motives and then build up a social system by aggregating motives. This approach has been rejected in the psychological sciences. Time and time again attempts to study attitudes through introspection were lacking in verification [Allport 1985]. The reductionist approach has also been denied by the historical tide. The tide turned toward the welfare state. The claims of utility calculation and hedonism "when tested in the crucible of social policy, proved inadequate" [Allport 1985]. The scientific reliability of motives was soon questioned even for studying hunger, thirst, and the sex drive. (In any case, psychology never held that there was evidence of a "profit motive.")

With the development of social psychology, the idea that motives were operatives continued to lose credibility. The Encyclopedic Dictionary of Psychology states "in the early days of behavioral science, motivation was envisaged in terms of the drive that was necessary for the manifestation of behavior: sexual behavior was due to the sex drive, eating to the hunger drive, etc. This is no longer a prevalent view and it is generally recognized that it is not necessary to account for behavior in terms of motive force" [Harre 1983]. Today the concern is with attitudes and the role of social institutions in determining attitudes. "Attitudes are individual mental processes which determine both the actual and potential responses of each person in the social world" [Allport 1985]. Some, especially those in psychology, are more interested in the mental processes. Institutional economists are more interested in the responses and their origin in the social system. What are the responses to price changes? Females in the workplace? Blacks on the faculty? Safety devices in the meat packing plants? Innovations? It is the answers to these questions that articulate the economy. The attitudes originate from outside the individual, not from motives, or hedonistic urges, or utility. Social psychologist, William J. McGuire, in the latest Handbook of Social Psychology stated, "institutional structures have intended or unintended impacts on attitudes by determining the stim- 
ulus situations to which the person is exposed, the response options available, the level and type of motivation, and the scheduling of reinforcements" [McGuire 1985].

No object has meaning without reference to clustered social beliefs and attitudes. However beliefs are determinants rather than components of attitudes. A belief for equal treatment of persons influences human attitudes and responses toward particular persons such as blacks, males, and the handicapped. "Put another way, the objects and situations we encounter have meaning for us not only because of the attitudes they activate within us but also because they are perceived to be instrumental to realization (or to stand in the way of realization) of one or more social beliefs" [Rokeach 1978]. It is through the day-to-day attitudinal responses to signs and symbols that the person-to-person, person-to-technology, and person-to-environment relationships are maintained in an institutional arrangement.

The more affluent a society in money, technology, and information, the greater the risk that members will lose sight of basic beliefs in forming their attitudes. All three lead to change and have the tendency to make society more complex, and to add additional layers of authority. Everyday activities mold attitudes, and those everyday activities may have become inconsistent with basic beliefs and values. Without effective monitoring with social indicators, human actors may also misinterpret the correct response that the institutional norms are conveying. "In a traditional society, where the institutions are often stable over long periods, there is usually a close fit between cultural values and institutional actions. But in modern society, where institutions change rapidly, it can sometimes happen that the values and goals of a society are in conflict with institutional requirements" [Wright 1975].

Since attitudes are so crucial in determining action, it is fortunate for policymaking and social planning that they can be changed without serious disruption of the social system. "Attitudes, while important and generally resistant to change, nevertheless are of less connective importance to society and easier to change than the central beliefs" [Rokeach 1968]. Basic social beliefs are very difficult to change, while cultural values are unchangeable for policy purposes. The more transcendental the concept, the more social entities there are for expressing, reinforcing, and maintaining it, and thus the greater the connective importance.

\section{Tastes as Inconsequential Attitudes}

Commodity tastes are treated here as a special category of attitudes because they are related to the institution of demand. Although tastes have been given a lofty status in the classical tradition of economics, 
they are the least important of the attitude categories because they can be changed easily-usually with no impact on basic beliefs-and, therefore, are without serious consequences for the belief system or the social structure. This does not mean that tastes cannot have a profound effect. For example, tastes can have a deleterious effect on human health. The point is that those tastes can be changed without a deleterious effect on the social structure or belief system.

\section{Summary}

Values, Beliefs and Attitudes Related to Situations

A simplified summary of the relationships described above are contained in Figure 2. Since cultural values $V_{t}$ are transcendental, they are

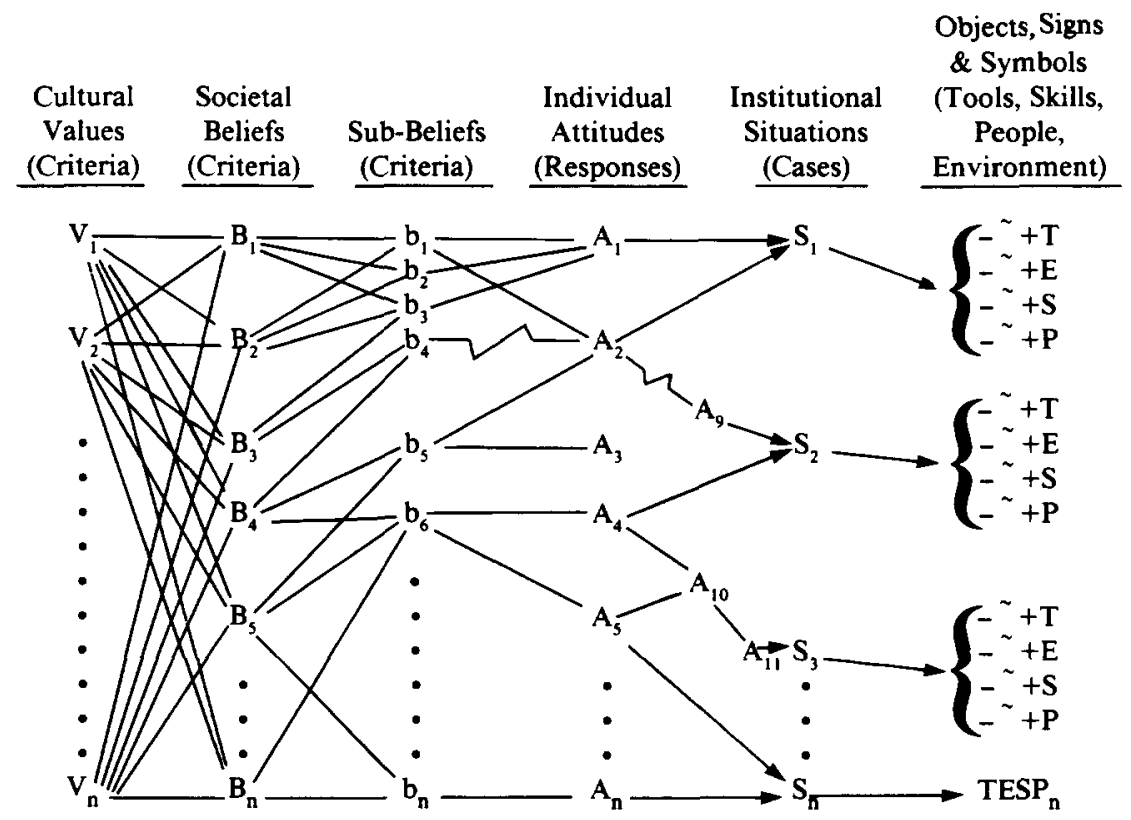

Symвors: $V_{1}-$ Values, $B_{1}-$ Beliefs, $b_{1}-$ sub-beliefs, $I_{1}$ - Institutions, $A_{1}-$ Attitudes,

$S_{1}$ - Situations, $T$ - Tools, E - Environmental Entities, $S$ - Skills,

$\mathrm{P}$ - People, $\sim-$ - Illegitimate, +- Permission, -- Prohibition,

- Obligation

Figure 2. Values, Beliefs and Attitudes Related to Situations 


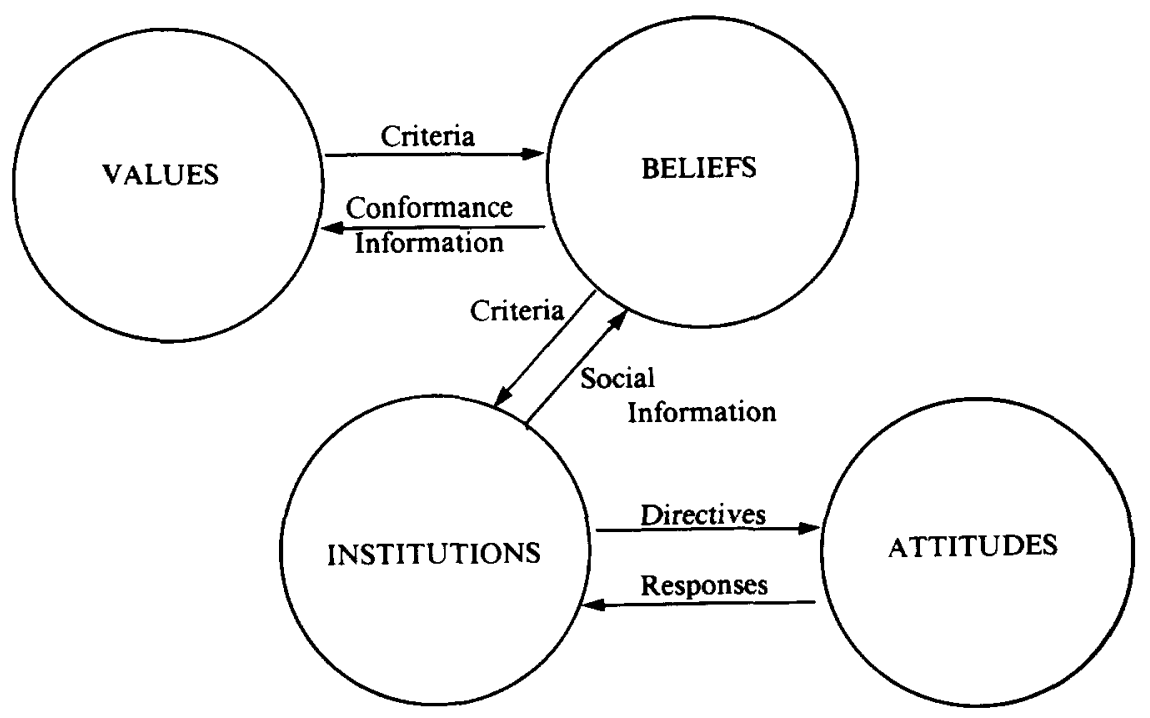

Figure 3. Social Fabric Digraph

related to all beliefs $\left(B_{t}\right)$. The values are not rank ordered. As Figure 2 indicates, basic cultural beliefs $\left(B_{l}\right)$ are related to specific sub-beliefs $b_{l}$ ). Particular beliefs are not related to all sub-beliefs or to all institutional activities. Clustered sub-beliefs determine attitudes $\left(A_{t}\right)$. For example $b_{1}, b_{2}$, and $b_{3}$ provides for $A_{1}$. Within a situation the elements $-T, E, S$ and $P$ ) respond to the objects, signs, and symbols of the situation according to response attitudes. "The argument is that person, situation, and behavior all affect each other continuously" [Allport 1985]. The elements have roles according to what they are prohibited from doing (-), permitted to do $(+)$, and obligated to do ( ). Each element would have the three roles of permission, prohibition, and obligation in each situation.

This approach is consistent with what John R. Commons did with a transaction. He disaggregated to an observable unit without attributing final motive to the elements; the sociocultural process was brought to bear on the transaction. Thus a transaction was observed as a process, not as an isolated artifact such as price. Commons took this ap- 
proach because of what he had learned from Charles Peirce regarding semiotics. Future analysis regarding values, beliefs, and attitudes should also turn to semiotics.

\section{Social Fabric Digraph}

In terms of the social fabric matrix and digraph, the deliveries among values, beliefs and attitudes are demonstrated in Figure 3. Cultural values deliver criteria to beliefs and receive information from beliefs with regard to whether there is alignment between the two. Therefore values do not make deliveries in any of the matrix cells except to beliefs.

Beliefs deliver criteria to institutions-only to the cells in the rows that intersect with the institutions' columns. Institutions deliver social information to beliefs to determine whether the institutions are in conformance with the beliefs. This informational connection is measured by social indicators. If we look at the banking industry as an example, there is an array of customary, legal, and judicial belief criteria established. The industry uses those in designing its structure, process, and procedures. The industry then provides directives to form the attitudes of its customers and employees.

Finally, attitudes, as displayed in Figure 3, receive directives from institutions and provide responses as stated above to the elements in the institutions.

\section{References}

Allport, Gordon W. 1985. "The Historical Background of Social Psychology." In Handbook of Social Psychology, Volume I: Theory and Method. Ed. Gardner Lindzey and Elliot Aronson, pp. 1-46. New York: Random House.

Bush, Paul D. 1987. "Theory of Institutional Change." Journal of Economic Issues 21 (September): 1075-1116.

Cawelti, John F. 1960. Adventure, Mystery, and Romance: Formula Stories as Art and Popular Culture. Chicago: University of Chicago Press.

Coon, Charles S. 1964. A Reader in Anthropology. New York: Holt, Rhinehart and Winston.

Falling, Harold. 1965. "A Proposal for the Empirical Study of Values." American Sociological Review 30 (April): 223-33.

Gjessing, Gutorm. 1968. Complementary, Value, and Social-Cultural Field. Bulletin No. 12. Olso: University-Forlaget.

Goldensen, Robert M. ed. 1984. Longman Dictionary of Psychology and Psychiatry. New York: Longman.

Harre, Rom, and Roger Lamb, eds. 1983. The Encyclopedia Dictionary of Psychology. Cambridge: MIT Press.

Hayden, F. Gregory. 1982a. "Social Fabric Matrix: From Perspective to Analytical Tool." Journal of Economic Issues 16 (September): 637-61. 
1982b. "Organizing Policy Research Through the Social Fabric Matrix: A Boolean Digraph Approach." Journal of Economic Issues 16 (December): 1013-26.

1977. "Toward a Welfare Construct for Social Indicators." The American Journal of Economics and Sociology 36 (April): 129-46.

1985. "A Transdisciplinary Integration Matrix for Economics and Policy Analysis." Social Science Information 24 (December): 869-903.

Neale, Walter C. 1987. “Institutions.” Journal of Economic Issues 21 (September): $1177-1206$.

McGuire, William J. 1985. "Attitudes and Attitude Change." In Handbook of Social Psychology, Volume II: Special Fields and Applications. Ed. Gardner Lindzey and Elliot Aronson, pp. 233-346. New York: Random House.

Ramstad, Yngve. 1986. "A Pragmatist's Quest for Holistic Knowledge: The Scientific Methodology of John R. Commons." Journal of Economic Issues 20 (December): 1067-1105.

Rokeach, Milton. 1968. Beliefs, Attitudes, and Values: A Theory of Organization and Change. San Francisco: Jossey-Bass, Inc.

1973. The Nature of Human Values. New York: Free Press.

1978. "Some Unresolved Issues in Theories of Beliefs, Attitudes, and

Values." In Nebraska Symposium on Motivation, pp. 261-304. Lincoln: University of Nebraska Press.

Schneider, Louis. 1972. "Some Disgruntled and Controversial Comments on the Idea of Culture in the Social Sciences." Social Science Quarterly 53 (September): $377-92$.

Waller, William T. Jr. 1982. "The Evolution of the Veblenian Dichotomy." Journal of Economic Issues 16 (September): 757-72.

Williams, Robin M. 1970. American Society: A Sociological Interpretation. 3d ed. New York: Alfred A. Knopf.

Wolfman, Benjamin B., ed. 1973. Dictionary of Behavioral Sciences. New York: Van Nostrand Reinhold.

Wright, Georg H. von. 1968. An Essay in Deontic Logic and the General Theory of Action. Amsterdam: North Holland Publishing Company.

Wright, Will. 1975. Six Guns and Society: A Structural Study of the Western. Berkley: University of California Press. 